\title{
Cultivares de Milho (Zea mays L.) e Sorgo (Sorghum bicolor (L.) Moench.) para Ensilagem no Alto Vale do Itajaí, Santa Catarina
}

\author{
Jefferson Araujo Flaresso ${ }^{1}$, Celomar Daison Gross ${ }^{2}$, Edison Xavier de Almeida ${ }^{1}$
}

\begin{abstract}
RESUMO - O experimento foi conduzido por três anos na EPAGRI - Estação Experimental de Ituporanga, SC, com o objetivo de selecionar cultivares de milho e sorgo para ensilagem. Foram testados treze cultivares de milho e oito de sorgo, utilizando-se um delineamento em blocos completos casualizados com três repetições. O plantio foi realizado em parcelas de 6,0 m x 6,0 m. A colheita foi efetuada quando a planta atingia o estádio de grão farináceo. Os cultivares que se destacaram por rendimento, composição de espigas/ panículas e qualidade foram: milho, AG-1051, AG-5011, P-3069, XL-330, XL-678, C-805, C-808 e C-901, e sorgo -AG-2002, AG-2005, AG-2006, C-51, P-8118 e BR-700.
\end{abstract}

Palavras-chave: milho, sorgo, ensilagem, rendimento de matéria seca, proteína bruta, nutrientes digestíveis totais

\section{Evaluation of Corn (Zea mays L.) and Sorghum (Sorghum bicolor (L.) Moench.) Cultivars for Silage Production in the Alto Vale do Itajaí Region, Santa Catarina State, Brazil}

\begin{abstract}
A 3-year study was conducted at EPAGRI - Experimental Station of Ituporanga, SC - Brazil, to select corn and sorghum cultivars suitability for silage production. Thirteen and eight corn and sorghum cultivars were tested and allotted to a complete randomized block experimental design, with three replications. The planting was done in $6 \mathrm{~m} \times 6 \mathrm{~m}$ plot area. The harvest was done when the plant presented a dough stage of maturity. The evaluated characteristics included dry matter yield, crude protein, and total digestible nutrient and ear/whole plant weight ratio. The corn cultivars with the best results for dry matter yield, ears/ panicles composition and quality were: corn - AG-1051, AG-5011, P-3069, XL-330, XL-678, C-805, C-808 and C-901, and sorghum were AG-2002, AG-2005, AG-2006, C-51, P-8118 and BR-700.
\end{abstract}

Key Words: corn, sorghum, ensiling, dry matter yield, crude protein, total digestible nutrient

\section{Introdução}

A região do Alto Vale do Itajaí, Santa Catarina, caracteriza-se pela presença de pequenas propriedades localizadas geralmente em solo de relevo declivoso. Nesses estabelecimentos, a atividade agropecuária é diversificada, sendo destaque a pecuária leiteira.

Em razão da estacionalidade da produção forrageira das pastagens da região, torna-se necessário a prática da suplementação alimentar, principalmente no outono e no inverno. Para amenizar esse problema, é cada vez mais comum a prática da confecção de silagem, tendo-se verificado a produção de cerca de cem mil toneladas desse produto na região no ano de 1997, segundo informação do serviço de extensão rural da região. Entre as várias plantas que se prestam à produção de silagem, têm-se recomendado o milho e o sorgo, devido às suas características de alto rendimento, boa qualidade e sua relativa facilidade de fermentação no silo. Segundo ALMEIDA et al. (1993a), as forrageiras mais empregadas para ensilagem no Alto Vale do Itajaí são o milho, sorgo e capim-elefante, sendo as produtividades médias de matéria seca em um corte de 7120, 13292 e $9786 \mathrm{~kg} / \mathrm{ha}$, respectivamente. Para uma produção adequada de silagem, é fundamental que se tenha à disposição do produtor a recomendação de espécies e cultivares com melhor qualidade e potencial produtivo. Nesse sentido, ALMEIDA et al. (1993b) avaliaram no Alto Vale do Itajaí nove cultivares de sorgo, três de milho, um de milheto e um de teosinto e obtiveram média de 13,7 t/ha de matéria seca. Nesse experimento, o sorgo cv $\mathrm{Br} 506$ rendeu 20,5 t/ha, enquanto o milho AG 162 foi o destaque com 12,8 t/ha de matéria seca. TCACENCO et al. (1989), em experimento conduzido na Estação Experimental de Itajaí, observaram que as porcentagens de proteína bruta e nutrientes digestíveis totais foram bem mais

\footnotetext{
1 Pesquisador da EPAGRI, Estação Experimental de Ituporanga, Cx. postal 121, CEP 88400-000, Ituporanga - SC E.mail: flaresso@epagri.rct-sc.br; exa@epagri.rct-sc.br

2 Agente Técnico de Desenvolvimento, EPAGRI, Cx. postal 73, CEP 89160-000, Rio do Sul - SC.
} 
altas em panículas do que em caules e folhas de cinco cultivares de sorgos testados, sendo que as produções variaram de 7 a 14 t/ha de matéria seca. Nesse sentido, FREITAS (1990), testando cultivares de milho, encontrou participação média de espigas em torno de $50 \%$ e concluiu que, quanto maior esse valor, melhor seria o valor energético da silagem.

No Planalto Catarinense, SOUZA (1989), trabalhando com 12 cultivares precoces e 15 tardios de milho, encontrou rendimentos médios de $11,2 \mathrm{e}$ $14,3 \mathrm{t} /$ ha de matéria seca e relação espiga/planta de 48,3 e $47,2 \%$, respectivamente, sendo o valor nutritivo médio obtido de 7,2\% de proteína bruta e 59,6\% de nutrientes digestíveis totais. Nessa mesma região, SILVA et al. (1994) avaliaram as cultivares C-501, Agroeste S-394, Agroeste BR-201, Agroeste BR451 e Azteca e obtiveram rendimentos de 9,4; 10,9; 11,$3 ; 10,3 ; \mathrm{e} ; 13 \mathrm{t} / \mathrm{ha}$ de matéria seca, respectivamente. Em outro experimento semelhante CECATO et al. (1994), em Maringá, PR, testaram 12 híbridos de sorgo e concluíram que os cultivares AG-2002 e BR-601 foram os mais produtivos, porém com menor produtividade de panículas e relação folha/haste que os demais. Destacaram os híbridos DK-861, DK-48 e CS-Silo-3 em relação à produção de panículas e o cultivar P-855-S com melhor relação folha/haste.

Conforme citado anteriormente, nos últimos anos, foram desenvolvidos alguns trabalhos de competição de cultivares, porém tem-se percebido que a região do Alto Vale do Itajaí carece de recomendações de forrageiras com maior rendimento e qualidade para ensilagem, o que se constituiu no principal objetivo deste trabalho.

\section{Material e Métodos}

O trabalho foi desenvolvido na EPAGRI Empresa de Pesquisa Agropecuária e Extensão Rural de Santa Catarina, Estação Experimental de Ituporanga - SC, localizada na região do Alto Vale do Itajaí, SC, com altitude de 475 m e clima subtropical úmido (Cfa), segundo a classificação de Köeppen.

O solo era um Cambissolo Distrófico Álico, com topografia suave ondulada, que recebeu preparo convencional, calagem e adubação conforme recomendações de BARTZ et al. (1994) para produção de silagem. As características químicas do solo na implantação da safra 1995/96 foram: pH água: 5,4; pH SMP: 5,5; P: 1,8 ppm; K: 35 ppm; MO: 4,2\%; Al: 0,4 me/dL; $\mathrm{Ca}+\mathrm{Mg}$ : 6,0 me/dL. A calagem foi realizada aplicando-se 5,5 t/ha de calcário. $\mathrm{Na}$ implantação em 18/10/95 foram aplicados $10 \mathrm{~kg} / \mathrm{ha}$ de nitrogênio, $190 \mathrm{~kg} / \mathrm{ha}$ de $\mathrm{P}_{2} \mathrm{O}_{5}$ e $250 \mathrm{~kg} / \mathrm{ha}$ de $\mathrm{K}_{2} \mathrm{O}$. Houve duas aplicações de nitrogênio em cobertura na dose de $60 \mathrm{~kg} / \mathrm{ha}$, um em 27/11/95 e outra em 09/01/96. Na implantação da safra 1996/97, as características químicas do solo foram: $\mathrm{pH}$ água: 5,7; pH SMP: 5,7; P: 16 ppm; K: 95 ppm; MO: 4,7\%; Al: 0,0 me/dL; $\mathrm{Ca}+\mathrm{Mg}: 12 \mathrm{me} / \mathrm{dL}$. Nessa área não foi feita $\mathrm{e}$ calagem e, na implantação em 28/10/96, foram aplicados $20 \mathrm{~kg} / \mathrm{ha}$ de nitrogênio, $100 \mathrm{~kg} / \mathrm{ha}$ de $\mathrm{P}_{2} \mathrm{O}_{5}$ e $150 \mathrm{~kg} / \mathrm{ha}$ de $\mathrm{K}_{2} \mathrm{O}$. O nitrogênio em cobertura foi aplicado em duas doses de $50 \mathrm{~kg} / \mathrm{ha}$ em 06/12/96 e 17/12/96. Para a safra 1997/98, o solo apresentava as seguintes características químicas: pH água: 6,1; pH SMP: 6,0; P: 5 ppm; K: 102 ppm; MO: 2,2\%; Al: 0,0 me/dL; $\mathrm{Ca}+\mathrm{Mg}: 14,7 \mathrm{me} / \mathrm{dL}$. Nessa área, não foi realizada calagem, sendo que na implantação em 12/11/97 foram aplicados $20 \mathrm{~kg} / \mathrm{ha}$ de nitrogênio, $150 \mathrm{~kg} / \mathrm{ha}$ de $\mathrm{P}_{2} \mathrm{O}_{5} \mathrm{e}$ $150 \mathrm{~kg} / \mathrm{ha}$ de $\mathrm{K}_{2} \mathrm{O}$. Em cobertura foram utilizados $70 \mathrm{~kg} / \mathrm{hade}$ nitrogênio aplicados em 19/12/97 e 10/01/98.

Os cultivares de milho (Zea mays L.) e sorgo (Sorghum bicolor (L.) Moench.) que foram testados nas safras 1995/96, 1996/97 e 1997/98 encontram-se listados na Tabela 1. O plantio foi feito em linhas espaçadas de 1,0 m, com desbastes para manter

Tabela 1 - Cultivares de milho e sorgo testados no experimento. Safras 1995/96, 1996/97 e 1997/98

Table 1 - Corn and sorghum cultivars evaluated in the experiment. Harvests of 1995/96, 1996/97, 1997/98

\begin{tabular}{|c|c|c|c|}
\hline \multirow[t]{2}{*}{$\begin{array}{l}\text { Espécie/Cultivar } \\
\text { Specie/Cultivar }\end{array}$} & \multicolumn{3}{|c|}{$\begin{array}{c}\text { Ano* } \\
\text { Year }\end{array}$} \\
\hline & $1995 / 96$ & $1996 / 97$ & $1997 / 98$ \\
\hline$\overline{Z e a m a y s-\mathrm{AG}-1051}$ & + & + & + \\
\hline Zea mays-AG-122 & + & + & + \\
\hline Zea mays-AG-5011 & + & + & + \\
\hline Zea mays-AG-519 & + & + & + \\
\hline Zea mays-C-805 & + & + & + \\
\hline Zea mays -C-806 & - & - & + \\
\hline Zea mays -C-808 & + & + & - \\
\hline Zea mays - C-901 & + & + & + \\
\hline Zea mays - P-3069 & + & + & + \\
\hline Zea mays - P-3232 & + & - & - \\
\hline Zea mays - XL-330 & + & + & + \\
\hline Zea mays - XL-660 & + & + & + \\
\hline Zea mays - XL-678 & + & - & - \\
\hline Sorghum bicolor - AG-2002 & + & + & + \\
\hline Sorghum bicolor-AG-2005 & - & - & + \\
\hline Sorghum bicolor - AG-2006 & + & + & - \\
\hline Sorghum bicolor - BR-700 & - & - & + \\
\hline Sorghum bicolor - C-51 & - & + & + \\
\hline Sorghum bicolor - DK-915 & + & + & + \\
\hline Sorghum bicolor - DK-916 & + & + & - \\
\hline Sorghum bicolor - P-8118 & - & + & + \\
\hline
\end{tabular}


1610 Rev. bras. zootec.

populações de 60.000 e 120.000 plantas por hectare para milho e sorgo, respectivamente. As unidades experimentais foram constituídas de parcelas de $6,0 \mathrm{~m} \times 6,0 \mathrm{~m}$ (área útil de 4,0 m x 4,0 m). O delineamento estatístico utilizado foi em blocos completos ao acaso com três repetições.

A colheita de milho e sorgo era feita manualmente por meio de cortes a $10 \mathrm{~cm}$ da superfície do solo, no estádio de grão farináceo. A quantidade colhida era pesada e, em seguida, eram utilizadas subamostras de 15 plantas de milho e 20 plantas de sorgo, nas quais era feita a separação em folhas, colmos, material morto, espigas/panículas e palha, os quais eram pesados e secados em estufa a $60^{\circ} \mathrm{C}$ por aproximadamente 72 horas, para obtenção da porcentagem de matéria seca. Além da determinação do rendimento dos diversos componentes, foram avaliados também parâmetros de época de colheita, altura das plantas e número de plantas acamadas. Para análise bromatológica, procedeu-se à moagem do material seco utilizando-se um moinho tipo Willey com peneira de $1 \mathrm{~mm}$ de malha. Os parâmetros qualitativos foram: proteína bruta-PB (ASSOCIATION OF OFFICIAL ANALYTICAL CHEMISTS AOAC, 1970), digestibilidade in vitro da matéria orgânica - DIVMO (PIRES et al., 1979) e nutrientes digestíveis totais - NDT (MINISTRY OF AGRICULTURE, FISHERIES AND FOOD, 1977).

\section{Resultados e Discussão}

Na Tabela 2 são apresentados os rendimentos totais de matéria seca obtidos nas três safras com suas respectivas médias. Na safra 1995/96, destacaram-se os cultivares de sorgo AG-2002 e DK-915 e os cultivares de milho AG-1051, AG-5011 e XL-678, não havendo diferença significativa entre os mesmos. No ano seguinte (1996/97) foram obtidos os maiores rendimentos em função das melhores condições do solo em que as plantas se desenvolveram. Nessa safra os materiais mais produtivos foram AG-2002, DK-915, DK-916, C-51 e AG-2006 entre os cultivares de sorgo e AG-1051, AG-519, XL-660, P-3069, XL-330, C-805 e C-901 entre os de milho. Na safra de 1997/98, o cultivar mais produtivo de sorgo foi o DK-915, o qual não diferiu estatisticamente do AG-2002, o qual foi semelhante aos cultivares C-51, P-8118 e BR-700, enquanto entre os milhos se destacaram os cultivares AG-5011 e XL-330, que não diferiram entre si e foram superiores aos materiais AG-519, AG-122, P-3069, C-901 e C-806, que não diferiram entre si. Considerando a média de três safras, na Tabela 2, observa-se que, entre os materiais analisados, os cultivares de sorgo com maiores rendimentos foram AG-2002 e DK-915, enquanto para os cultivares de milho pode-se salientar AG-1051, AG5011, AG-519, P-3069 e XL-330. Os rendimentos médios observados na safra 1995/96 foram inferiores aos verificados por KEPLIN (1992), o qual obteve, em Castro, PR, na média de 13 híbridos de milho, rendimento de 19,8 t/ha de matéria seca, valor semelhante aos obtidos na safra 1996/97. Outro trabalho de avaliação de cultivares destacou rendimento médio para milho e sorgo menor que o obtido neste experimento (MOLINA et al., 1998), enquanto os resultados de VALENTE et al. (1984) foram semelhantes ao

Tabela 2 - Rendimento total de matéria seca de milho e sorgo para ensilagem. Safras de 1995/96, 1996/ 97, $1997 / 98$

Table 2 - Corn and sorghum dry matteryield for silage production. Harvests of 1995/96, 1996/97, 1997/98

\begin{tabular}{|c|c|c|c|c|}
\hline \multirow[t]{2}{*}{ Cultivar } & \multicolumn{4}{|c|}{$\begin{array}{c}\text { Rendimento MS }(\mathrm{kg} / \mathrm{ha}) \\
\text { DM yield }(\mathrm{kg} / \mathrm{ha})\end{array}$} \\
\hline & $1995 / 96$ & $1996 / 97$ & 1997/98 & $\begin{array}{c}\text { Média ** } \\
\text { Mean }\end{array}$ \\
\hline $\mathrm{AG}-2002(\mathrm{~S})+$ & $18325^{\mathrm{ab}}$ & $27461^{\mathrm{a}}$ & $19185^{\mathrm{ab}}$ & $21657^{\mathrm{a}}$ \\
\hline AG-1051 (M) & $17110^{\mathrm{ab}}$ & $23869^{a b}$ & 15010 & $18663^{\mathrm{bc}}$ \\
\hline DK-915(S) & $15705^{\mathrm{ab}}$ & $23944^{\mathrm{ab}}$ & $20460^{\mathrm{a}}$ & $20036^{\mathrm{ab}}$ \\
\hline AG-5011 (M) & $14564^{\mathrm{b}}$ & 20130 & $18937^{\mathrm{ab}}$ & $17877^{\mathrm{cd}}$ \\
\hline AG-519(M) & 14281 & $22309^{b}$ & $15542^{\mathrm{b}}$ & $17377^{\text {cde }}$ \\
\hline XL-660(M) & 12783 & $22217^{b}$ & 12577 & $15859^{\mathrm{e}}$ \\
\hline AG-122(M) & 12436 & 18092 & $15761^{\mathrm{b}}$ & $15429^{\mathrm{e}}$ \\
\hline P-3069(M) & 12293 & $22207^{b}$ & $16324^{b}$ & $16941^{\text {cde }}$ \\
\hline XL-330(M) & 12150 & $21287^{b}$ & $17515^{\mathrm{ab}}$ & $16983^{\text {cde }}$ \\
\hline $\mathrm{C}-805(\mathrm{M})$ & 11473 & $21750^{\mathrm{b}}$ & 13567 & $15596^{\mathrm{e}}$ \\
\hline C-901 (M) & 10390 & $21227^{b}$ & $16327^{\mathrm{b}}$ & $15981^{\mathrm{de}}$ \\
\hline XL-678(M) & $14542^{\mathrm{b}}$ & $*$ & $*$ & 14542 \\
\hline P-3232(M) & 10710 & $*$ & * & 10710 \\
\hline DK-916(S) & 14016 & $25528^{\mathrm{ab}}$ & $*$ & 19772 \\
\hline $\mathrm{C}-808(\mathrm{M})$ & 11266 & 19727 & * & 15496 \\
\hline AG-2006(S) & 10430 & $21727^{b}$ & $*$ & 16079 \\
\hline $\mathrm{C}-51(\mathrm{~S})$ & $*$ & $23698^{\mathrm{ab}}$ & $16593^{b}$ & 20145 \\
\hline P-8118(S) & * & 15774 & $16449^{b}$ & 16112 \\
\hline BR-700(S) & $*$ & $*$ & $16261^{b}$ & 16261 \\
\hline $\mathrm{C}-806(\mathrm{M})$ & * & * & 14087 & 14087 \\
\hline AG-2005(S) & $*$ & $*$ & 14691 & 14691 \\
\hline
\end{tabular}

Médias na mesma coluna, seguidas da mesma letra, não diferem $(P>0,05)$.

$+(\mathrm{M})$ - Milho.

+ (S) - Sorgo.

* - Não-avaliado.

** - Comparação entre médias somente dos cultivares avaliados nos três anos.

Means in the same column followed by the same letter are not different $(P>$.05).

$+(M)-$ Corn.

$+(S)$ - Sorghum

* - Not tested.

** - Comparison among only cultivars tested in the three years. 
deste trabalho. Essa variação em termos de resultados está relacionada com as variações edafoclimáticas de cada região onde foram conduzidos os trabalhos, fato observado com a diferença obtida nas três safras conduzidas neste experimento.

$\mathrm{Na}$ Tabela 3, observa-se que o ciclo das plantas do plantio à colheita foi de 128, 122, 119, 121 e 119 dias paras os cultivares de sorgo mais tardios AG-2002, DK-915, DK-916, AG-2006 e BR-700, respectivamente. Esses cultivares de sorgo tenderam a apresentar maior altura em relação aos mais precoces, que foram colhidos com 103 dias (P-8118), 112 dias (C-51) e 113 dias (AG-2005). Com relação aos cultivares de milho, observou-se o ciclo em torno de 120 dias para os mais tardios (XL-678, AG-1051), próximo de 110 dias para os intermediários (XL-660, AG-519, P-3232, AG-5011) e próximo a 100 dias para os mais precoces (C-806, AG-122, C-805, C901, P-3069, XL-330). No caso dos cultivares de milho, também houve tendência de os materiais mais tardios apresentarem maior altura que os mais precoces, enquanto em relação ao parâmetro número de espigas por planta, observou-se tendência de igualdade, com valores próximos a um. Nos cultivares de sorgo, avaliando-se presença ou ausência de panícula, observou-se que a mesma se desenvolveu praticamente em todas as plantas. A resistência ao acamamento foi boa para a maioria dos materiais, exceto para os cultivares C-806, XL-660 e C-805 de milho e DK-915, DK-916 de sorgo (Tabela 3).

Para produção de silagem de melhor qualidade, é de fundamental importância o conhecimento da composição da planta em termos de colmo, folha, espiga e palha (Tabela 4). Com relação às plantas de milho, não houve diferenças acentuadas, havendo tendência de os materiais mais precoces como C-901, P-3069, C-805, AG-5011, XL-678 e C-805 apresentarem em torno de $30 \%$ de colmo em sua composição, contra o valor próximo a $35 \%$ de materiais mais tardios e mais altos, como AG-122, AG-1051, AG-519 e XL-660 (Tabela 4). Considerando que o colmo apresenta baix qualidade nutricional, os cultivares de sorgo que apresentaram menor participação desse componente na matéria seca foram o C-51, P-8118, AG-2005 e BR-700, 31,3;34,9;35,0; e 36,2\%, respectivamente, enquanto o AG-2002, DK-915 e DK-916 tiveram altos valores, 62,2; 51,2; e 49,0\%, respectivamente (Tabela 4). A proporção de colmo em plantas de

Tabela 3 - Dias entre plantio e colheita $\left(\mathrm{n}^{\circ}\right)$, altura $(\mathrm{cm})$, espigas e/ou panículas por planta ( $\left.\mathrm{n}^{\circ}\right)$ e percentagem de plantas acamadas de milho e sorgo para ensilagem

Table 3 - Days between seeding and harvest $\left(n^{\circ}\right)$, height $(\mathrm{cm})$, ear and/or panicle per plant (number) and lodged plants percentage of corn and sorghum for silage production

\begin{tabular}{|c|c|c|c|c|}
\hline Cultivar & $\begin{array}{c}\text { Plantio/Colheita (dias) } \\
\text { Seeding/harvest (days) }\end{array}$ & $\begin{array}{l}\text { Altura }(\mathrm{cm}) \\
\text { Height }(\mathrm{cm})\end{array}$ & $\begin{array}{c}\text { Espiga/Panícula }\left(\mathrm{n}^{\circ}\right) \\
\text { Ear/panicle }\left(n^{o}\right)\end{array}$ & $\begin{array}{c}\text { Planta acamada (\%) } \\
\text { Lodged plant }\end{array}$ \\
\hline$\overline{\mathrm{AG}-1051(\mathrm{M})^{\mathrm{a} * * *}}$ & 117 & 309 & 0,8 & 8,3 \\
\hline AG-122(M)*** & 103 & 286 & 0,9 & 3,0 \\
\hline $\mathrm{AG}-5011(\mathrm{M})^{* * *}$ & 106 & 265 & 0,9 & 1,7 \\
\hline AG-519(M)*** & 111 & 302 & 0,8 & 7,6 \\
\hline $\mathrm{C}-805(\mathrm{M}) * * *$ & 102 & 271 & 0,8 & 15,6 \\
\hline $\mathrm{C}-806(\mathrm{M})^{*}$ & 98 & 281 & 0,7 & 43,2 \\
\hline $\mathrm{C}-808(\mathrm{M}) * *$ & 103 & 271 & 0,9 & 0,0 \\
\hline $\mathrm{C}-901(\mathrm{M})^{* * *}$ & 100 & 254 & 0,9 & 2,5 \\
\hline $\mathrm{P}-3069(\mathrm{M})^{* * *}$ & 101 & 260 & 0,9 & 5,9 \\
\hline P-3232(M)* & 107 & 278 & 0,9 & 0,0 \\
\hline $\mathrm{XL}-330(\mathrm{M}) * * *$ & 105 & 285 & 0,9 & 2,2 \\
\hline XL-660(M)*** & 111 & 292 & 0,8 & 23,6 \\
\hline XL-678(M)* & 121 & 245 & 0,9 & 0,7 \\
\hline AG-2002(S) $)^{\mathrm{b} * * *}$ & 128 & 343 & 0,8 & 10,3 \\
\hline AG-2005(S)* & 113 & 194 & 0,9 & 0,0 \\
\hline AG-2006(S)** & 121 & 239 & 0,9 & 0,0 \\
\hline BR-700 $(\mathrm{S})^{*}$ & 119 & 221 & 0,8 & 0,0 \\
\hline $\mathrm{C}-51(\mathrm{~S})^{* *}$ & 112 & 184 & 0,9 & 0,0 \\
\hline DK-915 $(\mathrm{S})^{* * *}$ & 122 & 303 & 0,8 & 55,8 \\
\hline DK-916(S)** & 119 & 288 & 0,9 & 50,0 \\
\hline $\mathrm{P}-8118(\mathrm{~S})^{* *}$ & 103 & 151 & 0,9 & 0,0 \\
\hline
\end{tabular}

a (M) - Milho. b (S) - Sorgo; * 1 ano de avaliação; ** 2 anos de avaliação; *** 3 anos de avaliação.

$a$ (M) Corn; $b$ (S) Sorghum; * Tested for one year; ${ }^{* *}$ Tested for two years; ${ }^{* *}$ Tested for three years. 
1612 Rev. bras. zootec.

milho encontrada neste experimento está acima da obtida por KEPLIN (1992) para materiais de porte baixo $(24,1 \%)$ e semelhante para os materiais de porte alto $(40,2 \%)$. Já para os cultivares de sorgo, os resultados deste experimento são semelhantes aos obtidos por MOLINA et al. (1998), em que os materiais variaram de 40,5 a $67 \%$ de colmo em sua composição. No que diz respeito à participação de folhas, observam-se na Tabela 4 os maiores valores para os milhos XL-660, AG-122 e AG-5011 com 18,9; 17,5; e 17,3\% de folhas em sua composição, respectivamente. Os cultivares de sorgo que se destacaram foram C-51, P-8118 e AG-2006 com 17,9; 17,3; e $16,8 \%$. Observa-se ainda que as diferenças entre os materiais em termos de folhas não foram muito significativas, exceção feita para os cultivares de sorgo AG-2002 e DK-915, que apresentaram menores valores, em torno de $12 \%$ (Tabela 4). HENRIQUE et al. (1994) encontraram para cultivares de milho participação de folhas variando de 14,6 a $16,1 \%$, os quais foram semelhantes aos obtidos neste trabalho. Na comparação com os sorgos avaliados neste ensaio, os resultados de MOLINA et al. (1998) variaram de 12,1 a $21,6 \%$ de participação de folhas, sendo também próximos aos deste experimento. Na produção de silagem de alta energia, a espiga é o componente mais importante. Na Tabela 4, destacam-se os seguintes cultivares de milho: C-901, P-3069, C-805, XL-678, C-808, AG-1051, XL-330, AG-1051 e C-806, com 47,0; 44,1; 42,9; 42,4; 41,4; 41,1; 40,7; 39,6; e $38,6 \%$, respectivamente. Já para os cultivares de sorgo, salientam-se os cultivares C-51, AG-2005, P-8118 e BR-700 com 48,9; 47,4; 47,0; e 43,9\% de espigas em sua composição, respectivamente. Ob-

Tabela 4 - Participação de colmo (\%), folha (\%), espiga e/ou panícula (\%), palha (\%) e material morto (\%) nos cultivares de milho e sorgo para ensilagem

Table 4 - Percentage of stem, leaf, ear and/or panicle, husk and dead material in the corn and sorghum cultivars for silage production

\begin{tabular}{|c|c|c|c|c|c|}
\hline Cultivar & $\begin{array}{l}\text { Colmo } \\
(\%) \\
\text { Stem }\end{array}$ & $\begin{array}{c}\text { Folha } \\
(\%) \\
\text { Leaf }\end{array}$ & $\begin{array}{c}\text { Espiga } \\
(\%) \\
\text { Ear }\end{array}$ & $\begin{array}{c}\text { Palha } \\
(\%) \\
\text { Husk }\end{array}$ & $\begin{array}{c}\text { Material morto } \\
(\%) \\
\text { Dead material }\end{array}$ \\
\hline $\mathrm{AG}-1051(\mathrm{M})^{\mathrm{a} * * *}$ & 34,9 & 14,8 & 41,1 & 7,7 & 1,4 \\
\hline $\mathrm{AG}-122(\mathrm{M}) * * *$ & 37,8 & 17,5 & 33,0 & 11,0 & 0,7 \\
\hline $\mathrm{AG}-5011(\mathrm{M})^{* * *}$ & 33,2 & 17,3 & 39,6 & 9,3 & 0,6 \\
\hline $\mathrm{AG}-519(\mathrm{M}) * * *$ & 37,4 & 14,6 & 36,4 & 10,6 & 0,9 \\
\hline $\mathrm{C}-805(\mathrm{M}) * * *$ & 33,4 & 14,7 & 42,9 & 8,9 & 0,0 \\
\hline $\mathrm{C}-806(\mathrm{M})^{*}$ & 36,3 & 16,1 & 38,6 & 8,9 & 0,0 \\
\hline $\mathrm{C}-808(\mathrm{M})^{* *}$ & 33,9 & 16,1 & 41,4 & 8,5 & 0,0 \\
\hline $\mathrm{C}-901(\mathrm{M}) * * *$ & 29,2 & 15,4 & 47,0 & 8,3 & 0,1 \\
\hline P-3069(M)*** & 31,6 & 15,5 & 44,1 & 8,7 & 0,1 \\
\hline $\mathrm{P}-3232(\mathrm{M})^{*}$ & 35,1 & 16,7 & 36,3 & 11,8 & 0,0 \\
\hline XL-330(M)*** & 34,4 & 14,3 & 40,7 & 10,5 & 0,0 \\
\hline XL-660 (M *** & 35,7 & 18,9 & 34,6 & 9,8 & 1,0 \\
\hline XL-678(M)* & 31,8 & 15,7 & 42,4 & 9,3 & 0,8 \\
\hline AG-2002(S) $)^{\mathrm{b} * * *}$ & 62,2 & 11,8 & 22,7 & - & 3,3 \\
\hline AG-2005 (S)* & 35,0 & 15,4 & 47,4 & - & 2,1 \\
\hline AG-2006(S)** & 46,7 & 16,8 & 34,8 & - & 1,6 \\
\hline BR-700(S)* & 36,2 & 15,6 & 43,9 & - & 4,2 \\
\hline $\mathrm{C}-51(\mathrm{~S})^{* *}$ & 31,3 & 17,9 & 48,9 & - & 1,9 \\
\hline DK-915(S)*** & 51,2 & 11,6 & 35,8 & - & 1,5 \\
\hline DK-916(S)** & 49,0 & 14,4 & 35,4 & - & 1,1 \\
\hline $\mathrm{P}-8118(\mathrm{~S}) * *$ & 34,9 & 17,3 & 47,0 & - & 0,7 \\
\hline
\end{tabular}

a - (M) - Milho.

b - (S) - Sorgo.

* $\quad$ - 1 ano de avaliação.

** -2 anos de avaliação.

*** - 3 anos de avaliação.

a - (M) - Corn.

b - (S) - Sorghum

* - Tested for one year.

** - Tested for two years.

$* * *$ - Tested for three years. 
serva-se tanto para milho como para sorgo tendência de os materiais de porte baixo apresentarem maior expressão para o componente espiga, fato também observado por KEPLIN (1992). Esse autor encontrou em seus trabalhos valores de participação de espigas em milho mais altos que os obtidos neste trabalho, ou seja, variação de 45,0 a $67,2 \%$, enquanto SILVA et al. (1994) verificaram valores mais próximos, variando de 29,5 a 41,4\% para o componente espiga. Para os cultivares de sorgo, os resultados deste trabalho são semelhantes aos obtidos por MOLINA et al. (1998), que encontraram variação de 20,9 a 40,6\% de panículas. A palha é o componente de proteção na espiga, sendo nutricionalmente de baixa qualidade. Na Tabela 4 observa-se variação de $7,7 \%$ de palha no cultivar de milho AG-1051 até $11,8 \%$ no cultivar P-3232. KEPLIN (1992) encontrou maior variação nos híbridos avaliados (6,7 a 17,2\%), sendo a média de $12,4 \%$ do componente palha superior àquela encontrada neste experimento. Segundo esse autor, o teor de palha ideal deve estar em torno de $7,4 \%$. Com relação ao componente material morto, não se encontrou teor elevado nos cultivares estudados, evidenciando o aspecto de as folhas permanecerem verdes até a colheita e mantendo, assim, a qualidade do material a ser ensilado (Tabela 4).

Nas Tabelas 5 e 6 encontram-se os parâmetros qualitativos de proteína bruta (PB\%), digestibilidade in vitro da matéria orgânica (DIVMO\%) e nutrientes digestíveis totais (NDT\%) obtidos nas safras de 1995/96 e 1996/97. Segundo KEPLIN (1992), uma silagem para ser considerada de boa qualidade deve apresentar de 7,1 a 8\% de PB e 64 a 70\% de NDT. Para a safra 1995/96, observa-se que, em termos de $\mathrm{PB} \%$, quase todos os materiais atingiram valores satisfatórios, exceto o sorgo AG-2002, com 6,3\% ( Tabela 5). O valor médio de PB\% foi maior para os cultivares de milho comparativamente aos de sorgo, 8,3 e $7,1 \%$, respectivamente. HENRIQUE et al. (1994) encontraram teores de $\mathrm{PB} \%$ para milho de 8,3 a $9,0 \%$, sendo, portanto, semelhante ao encontrado neste ensaio. Em contrapartida, QUADROS et al. (1994) verificaram valores de PB\% inferiores, variando de 5,1 a $6,5 \%$ para milho e 4,9 a $7,5 \%$ para sorgo. Para a safra 1996/97, os valores encontrados de $\mathrm{PB} \%$ foram semelhantes à safra 1995/96, apenas que os cultivares de sorgo tenderam a apresentar valores maiores, o que igualou à média em relação ao milho (Tabela 6). Na avaliação do NDT\%, observa-se nas Tabelas 5 e 6 que, de maneira geral, os cultivares de milho e sorgo apresentaram valores abaixo
Tabela 5 - Proteína bruta (PB\%), digestibilidade in vitro da matéria orgânica (DIVMO\%) e nutrientes digestíveis totais (NDT\%) de milho e sorgo para ensilagem. Safra 1995/96

Table 5 - Crude protein (CP\%), in vitro organic matter disappearance (IVDOM\%) and total digestible nutrients (TDN\%) of corn and sorghum for silage production. Harvest of 1995/96

\begin{tabular}{lccc}
\hline Cultivar & $\begin{array}{c}\text { PB\% } \\
C P\end{array}$ & $\begin{array}{c}\text { DIVMO\% } \\
\text { IVDOM }\end{array}$ & $\begin{array}{c}\text { NDT\% } \\
\text { TDN }\end{array}$ \\
\hline AG-1051(M)* & 7,9 & 54,7 & 53,2 \\
AG-122(M) & 8,6 & 62,9 & 59,3 \\
AG-5011(M) & 8,8 & 59,2 & 57,0 \\
AG-519(M) & 8,4 & 53,1 & 51,4 \\
C-805(M) & 8,4 & 60,9 & 59,0 \\
C-808(M) & 7,9 & 61,6 & 59,5 \\
C-901(M) & 8,2 & 56,2 & 54,0 \\
P-3069(M) & 8,7 & 61,5 & 58,9 \\
P-3232(M) & 7,7 & 57,7 & 54,8 \\
XL-330(M) & 8,3 & 61,2 & 59,1 \\
XL-660(M) & 8,9 & 60,9 & 59,8 \\
XL-678(M) & 7,8 & 57,7 & 55,9 \\
Média milho & 8,3 & 58,9 & 56,8 \\
Corn mean & & & \\
AG-2002(S)** & 6,3 & 53,8 & 55,8 \\
AG-2006(S) & 7,7 & 65,7 & 62,7 \\
DK-915(S) & 7,1 & 49,4 & 47,5 \\
DK-916(S) & 7,4 & 56,6 & 54,3 \\
Média sorgo & 7,1 & 56,8 & 55,3 \\
Sorghum mean & & & \\
\hline
\end{tabular}

* (M) - Milho

** (S) - Sorgo

* (M) - Corn

** (S) - Sorghum

daqueles recomendados para silagem de boa qualidade, segundo autores como FREITAS (1990) e KEPLIN (1992). Na safra 1995/96, cabe destacar alguns materiais com NDT próximo a $60 \%$ como XL-660, C-808, AG-122, XL-330 e P-3069 entre os cultivares de milho e AG-2006 entre os cultivares de sorgo (Tabela 5). Segundo TCACENCO et al. (1989) e KEPLIN (1992), para se obter uma silagem de alta energia, o cultivar deve apresentar alta proporção de espigas, fato observado apenas em alguns materiais neste experimento. Os valores de NDT\% deste ensaio foram semelhantes aos obtidos por GOMIDE et al. (1987) e ALMEIDA et al. (1993b). Para a safra 1996/97, os valores de NDT\% tenderam a ser menores que os da safra anterior, $o$ que pode ser explicado pela obtenção de participação maior de colmo e menor de espigas (Tabela 6). Entre os cultivares de milho, destacaram-se C-901, XL-660 e XL-330 e, entre os cultivares de sorgo, o maior teor de NDT foi obtido na cultivar P-8118. 
Tabela 6 - Proteína bruta (PB\%), digestibilidade in vitro da matéria orgânica (DIVMO\%) e nutrientes digestíveis totais (NDT\%) de milho e sorgo para ensilagem. Safra 1996/97

Table 6 - Crude protein (CP\%), in vitro organic matter disappearance (IVDOM\%) and total digestible nutrients (TDN\%) of corn and sorghum for silage production. Harvest of 1996/97

\begin{tabular}{lccc}
\hline Cultivar & $\begin{array}{c}\text { PB\% } \\
C P\end{array}$ & $\begin{array}{c}\text { DIVMO\% } \\
\text { IVDOM }\end{array}$ & $\begin{array}{c}\text { NDT\% } \\
\text { TDN }\end{array}$ \\
\hline AG-1051(M)* & 8,5 & 58,3 & 56,2 \\
AG-122(M) & 7,3 & 52,6 & 50,4 \\
AG-5011(M) & 8,3 & 54,3 & 51,9 \\
AG-519(M) & 7,2 & 53,8 & 51,8 \\
C-805(M) & 7,4 & 56,7 & 54,5 \\
C-808(M) & 8,6 & 54,0 & 52,0 \\
C-901(M) & 8,2 & 64,1 & 61,8 \\
P-3069(M) & 8,8 & 58,0 & 55,4 \\
XL-330(M) & 7,5 & 59,7 & 57,7 \\
XL-660(M) & 7,6 & 60,3 & 58,1 \\
Média milho & 7,9 & 57,2 & 55,0 \\
Corn mean & & & \\
AG-2002(S)** & 6,4 & 54,8 & 56,2 \\
AG-2006(S) & 8,0 & 52,6 & 50,2 \\
DK-915(S) & 6,5 & 48,2 & 46,2 \\
DK-916(S) & 7,8 & 54,9 & 52,3 \\
P-8118(S) & 9,4 & 57,6 & 54,8 \\
C-51(S) & 9,1 & 53,3 & 50,2 \\
Média sorgo & 7,8 & 53,6 & 51,6 \\
Sorghum mean & & & \\
\hline
\end{tabular}

* (M) - Milho; ** (S) - Sorgo.

* (M) - Corn; ** (S) - Sorghum.

\section{Conclusões}

Em termos de rendimento forrageiro, qualidade e participação de espigas e/ou panículas, neste trabalho, destacaram-se os seguintes cultivares que poderão ser recomendados para ensilagem na região do Alto Vale do Itajaí, Santa Catarina: milhos AG-1051, AG-5011, P-3069, XL-330, XL-678, C-805, C-901 e C-808 e sorgos AG-2002, AG-2005, AG-2006, C-51, P-8118 e BR-700.

\section{Referências Bibliográficas}

ALMEIDA, E.X., GROSS, C.D., FLARESSO, J.A. et al. 1993a. Acompanhamento do processo de ensilagem no Alto Vale do Itajaí, Santa Catarina. Florianópolis, EPAGRI. p.61. (EPAGRI. DOCUMENTOS, 144).

ALMEIDA, E.X., TCACENCO, F.A., STUCKER, H. et al. 1993b. Avaliação de cultivares de sorgo, milho, milheto e teosinto para o Vale do Itajaí. Agropecuária Catarinense, 6(3):25-29.

ASSOCIATION OF OFFICIAL ANALYTICAL CHEMISTS AOAC. 1970. Official methods of analysis of the association of official analytical chemists. 11.ed. Washington, D.C. 1015p.

BARTZ, H.R., BISS ANI, C.A., SCHERER, E.E. et al. 1994 Recomendações de adubação e de calagem para os Estados do Rio Grande do Sul e de Santa Catarina. Passo Fundo, RS: EMBRAPA - CNPT. 224p.

CECATO, U., SAKAGUTI, E.S., DAMASCENO, J.C. et al. Avaliação de híbridos de sorgos para produção de silagem. IN: REUNIÃO ANUAL DA SOCIEDADE BRASILEIRA DE ZOOTECNIA, 31, 1994, Maringá, PR. Anais ... Maringá: SBZ, 1994. p.348.

FREITAS, E.A.G. 1990. Silagem de milho: condicionantes do valor nutritivo. Agropecuária Catarinense, 3(2):9-12.

GOMIDE, J.A. ZAGO, C.P., CRUZ, M.E. et al. 1987. Milho e sorgo em cultivos puros ou consorciados com soja, para produção de silagens. R. Soc. Bras. Zootec., 16(4):308-317.

HENRIQUE, W., PERES, R.M., VIANA, J.L. et al. Avaliação de três híbridos de milho para produção de silagem. In: REUNIÃO ANUAL DA SOCIEDADE BRASILEIRA DE ZOOTECNIA, 31, 1994, Maringá, PR. Anais ... Maringá: SBZ, 1994. p.343.

KEPLIN, L.A.S. 1992. Recomendação de sorgo e milho (silagem) safra 1992/93. ENCARTE TÉCNICO DA REVISTA BATAVO. CCLPL, Castro, PR. Ano I, n.8, p.16-19.

MINISTRY OF AGRICULTURE, FISHERIES AND FOOD. 1977. Energy allowances and feed sistems for ruminants. London. 79p. (Technical Bulletin, 33).

MOLINA, L.R., GONÇALVES, L.C., RODRIGUES, J.A.S. et al. Produção de matéria seca e das proporções de colmo, folha e panícula de seis híbridos de sorgo. In: REUNIÃO ANUAL DA SOCIEDADE BRASILEIRA DE ZOOTECNIA, 35, 1998, Botucatu, SP. Anais... Botucatu: SBZ, 1998, p.581-583.

PIRES, M.B.G., FREITAS, E.A.G., TRINDADE, D.S. et al. 1979. Estabelecimento de um sistema de digestibilidade "in vitro" no laboratório da equipe de pesquisa em nutrição animal da Secretaria da Agricultura. Anuário Técnico do Instituto de Pesquisas Zootécnicas "Francisco Osório", 6:345-385. 
QUADROS, F.L.F., GENRO, T.R.M., ARAUJO, B.E. et al. Qualidade da silagem de híbridos de milho (Zea mays) e sorgo (Sorghum sp.) In: REUNIÃO ANUAL DA SOCIEDADE BRASILEIRA DE ZOOTECNIA, 31, 1994, Maringá, PR. Anais... Maringá: SBZ, 1994. p.357.

SILVA, A.W.L., ALMEIDA, M.L., MAFRA, A.L. et al. Avaliação de híbridos e variedades de milho para ensilagem. I. Produtividade e características agronômicas. In: REUNIÃO ANUAL DA SOCIEDADE BRASILEIRA DE ZOOTECNIA, 31, 1994, Maringá, PR. Anais ... Maringá: SBZ, 1994. p.344.

SOUZA, S.N. 1989. Milho para silagem: considerações agronômicas. Agropecuária Catarinense, 2(2):11-14.
TCACENCO, F.A., SALERNO, A.R., HILlESHEIM, A. et al. 1989. O sorgo forrageiro no Vale do Itajaí. Agropecuária Catarinense, 2(3):37-39.

VALENTE, J.O., COELHO DA SILVA, J.F.C., GOMIDE, J.A. 1984. Estudo de duas variedades de milho (Zea mays L.) e de quatro variedades de sorgo, para ensilagem. 1. Produção e composição do material ensilado e das silagens. R. Soc. Bras. Zootec., 13(1):67-73.

Recebido em: 07/12/98

Aceito em: 12/05/00 